\title{
The empire strikes back: Surgical ventricular reconstruction works very well in Japan
}

\author{
Lorenzo A. Menicanti, MD
}

\author{
From the Cardiac Surgery Department, IRCCS Policlinico San Donato, Milano, Italy. \\ Disclosures: Author has nothing to disclose with regard to commercial support. \\ Received for publication July 14, 2018; accepted for publication July 16, 2018; available ahead of print Aug 29, \\ 2018. \\ Address for reprints: Lorenzo A. Menicanti, MD, Department of Cardiac Surgery, IRCCS Policlinico San Donato, \\ via Morandi 30, 20090 San Donato Milanese, Milano, Italy (E-mail: menicanti@libero.it). \\ J Thorac Cardiovasc Surg 2018;156:2097 \\ $0022-5223 / \$ 36.00$ \\ Copyright (C) 2018 by The American Association for Thoracic Surgery \\ https://doi.org/10.1016/j.jtcvs.2018.07.029
}

Left ventricular dilatation after an acute myocardial infarction is one of the major risks for mortality in follow-up period. Surgical ventricular restoration is the most effective therapeutic strategy to reduce the volume of a left ventricle that has been affected by scarring after acute myocardial infarction. The concept of this procedure is clear; it is intended to exclude from the cavity the portion of left ventricle wall that is enlarged because of a scar or thinning wall. ${ }^{1}$

The Surgical Treatment for Ischemic Heart Failure $(\mathrm{STICH})$ trial $^{2}$ randomly allocated patients with low ejection fraction and enlarged ventricle to 2 surgical treatment arms: coronary artery bypass grafting alone or coronary artery bypass grafting plus surgical ventricular reconstruction. The result was neutral: no difference was found in mortality at 5-year-follow-up between the studied procedures. $^{2}$ This result is in contrast with the literature dealing with this procedure, which yields clear evidence that an important survival advantage is achieved if the postoperative left ventricle volume is around $60 \mathrm{~mL} / \mathrm{m}^{2}$. Some years after the first STICH result publication, a post hoc analysis of the STICH data confirmed an important benefit in survival if the postoperative end systolic volume was equal to or less than $70 \mathrm{~mL} / \mathrm{m}^{2}$.

To confer an advantage, therefore, surgery must reach a target volume. In this issue of the Journal, Wakasa and coauthors $^{5}$ report the results of the Surgical Ventricular Reconstruction for Severe Ventricular Dysfunction registry (SURVIVE). In this multicenter study, 17 different hospitals in Japan collected data for patients with heart failure and left ventricular systolic dysfunction. The surgeons performed at least 4 different techniques, according to personal experience and preference. Different surgical techniques can achieve the same volume reduction, as demonstrated in this article. On the other side, not every ventricle reduces to target volume. The identification of the good candidate for this procedure depends on several baseline characteristics; echocardiography and magnetic resonance imaging are irreplaceable tools to define volume, transmurality and

\section{References}

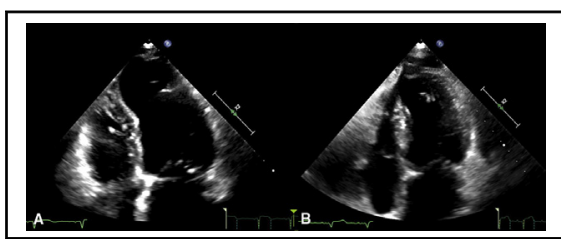

A, Preoperative end-systolic VI $74 \mathrm{~mL}$, EF 36\%; B, post-SVR end-systolic VI $35 \mathrm{~mL}$, EF $48 \%$.

Central Message

SVR reduces postischemic ventricular dilatation, and the benefit is linked to a target volume. This article describes an algorithm to predict postoperative volume and ejection fraction.

See Article page 2088.

extension of the scar, viable myocardium, and status of remote myocardium. The remote myocardium is the keystone to recovery; postoperative volume and shape affect function, but a good volume is clearly not enough for a good result. The central picture of the article of Wakasa and coauthors ${ }^{5}$ displays survival according to volume and ejection fraction. Patients with same volume have different outcomes according to ejection fraction. The goal of Wakasa and coauthors ${ }^{5}$ was to identify which patients can respond to the surgery, and they generated 2 equations predicting postoperative volume and ejection fraction.

The equations of Wakasa and coauthors ${ }^{5}$ can be an important tool in patient selection for this type of surgery, excluding patients who will not benefit from the procedure. Unfortunately, these equations have not been validated with an external patient cohort; we hope that in the future, a new study can validate these interesting data.

1. Menicanti L, Castelvecchio S. Left ventricular reconstruction concomitant to coronary artery bypass grafting: when and how? Curr Opin Cardiol. 2011;26:523-7.

2. Jones RH, Velazquez EJ, Michler RE, Sopko G, Oh JK, O'Connor CM, et al STICH Hypothesis 2 Investigators. Coronary bypass surgery with or without surgical ventricular reconstruction. N Engl J Med. 2009;360:1705-17.

3. Di Donato M, Castelvecchio S, Menicanti L. End-systolic volume following surgical ventricular reconstruction impacts survival in patients with ischemic dilated cardiomyopathy. Eur J Heart Fail. 2010;12:375-81.

4. Michler RE, Rouleau JL, Al-Khalidi HR, Bonow RO, Pellikka PA, Pohost GM, et al; STICH Trial Investigators. Insights from the STICH trial: change in left ventricular size after coronary artery bypass grafting with and without surgical ventricular reconstruction. J Thorac Cardiovasc Surg. 2013;146:1139-45.

5. Wakasa S, Matsui Y, Kobayashi J, Cho Y, Yaku H, Matsumiya G, et al. Estimating postoperative left ventricular volume: identification of responders to surgical ventricular reconstruction. J Thorac Cardiovasc Surg. 2018;156:2088-96.e3. 